\title{
Avaliação qualitativa do risco de poluição por metais potencialmente tóxicos nos sedimentos do empreendimento hidrelétrico de Foz do Rio Claro
}

\section{Qualitative evaluation of the risk of heavy metal pollution in the sediments of the Foz do Rio Claro hydroelectric plant}

\author{
Pollyanna Faria Nogueira* ${ }^{\star}(\mathbb{0}$, João Batista Pereira Cabral $₫(\mathbb{0}$, Michaela Andréa Bette \\ Camara $\times(1)$
}

Universidade Federal de Goiás, Regional Jataí, Goiás, Brasil

E-mail: jbcabral2000@yahoo.com.br (JBPC); macamara2@gmail.com (MABC)

Recebido (Received): 27/07/2020

*E-mail para correspondência: pollyannafnogueira@gmail.com

Aceito (Accepted): 09/02/2021

Resumo: O presente estudo teve como objetivo avaliar a concentração de metais potencialmente tóxicos Chumbo $(\mathrm{Pb})$, Zinco (Zi), Níquel $(\mathrm{Ni})$, Cobre $(\mathrm{Cu})$ e Cádmio $(\mathrm{Cd})$ - em amostras de sedimento coletadas no reservatório da UHE Foz do Rio Claro. Para avaliar os níveis de poluição, foram calculados o índice de geoacumulação (IGeo), além de utilizar os valores orientadores estabelecidos pela Resolução Conama 454/2012. De maneira geral, os elementos Cu e Cd apresentaram valores acima do nível II para a maioria dos pontos analisados, resultando na classificação de péssima qualidade dos sedimentos analisados. O cálculo do IGeo apontou a poluição do reservatório por $\mathrm{Cu}$ e $\mathrm{Cd}$. Este estudo evidenciou a necessidade de um monitoramento frequente da qualidade dos sedimentos no reservatório Foz do Rio Claro, como procedimento indispensável para avaliação periódica da qualidade da bacia, considerando sua importância no fornecimento de água e geração de energia para o estado de Goiás.

Palavras-chave: Cobre; Cádmio; Reservatório; Índice de Geoacumulação.

Abstract: The objective of this study was to evaluate the concentration of toxic metals Lead (Pb), Zinc (Zi), Nickel (Ni), Copper (Cu), and Cadmium (Cd), in sediment samples collected in the UHE Foz do Rio Claro reservoir. To evaluate the levels of contamination, we calculated the geoaccumulation index (IGeo), as well as the oriented values established by Conama Resolution 454/2012 resolution. In general, the elements $\mathrm{Cu}$ and Cd presented values above level II for most sampling points, resulting in the classification of bad quality of the sediments analyzed. The Igeo values indicated the contamination of $\mathrm{Cu}$ and $\mathrm{Cd}$. This study evidenced the need for frequent monitoring of the sediment quality in the Foz do Rio Claro reservoir, as an indispensable procedure for periodic evaluation of the basin quality, considering their importance for State of the Goiás water supply and energy generation.

Keywords: Copper; Cadmiu;, Reservoir; Geoccumulation Index.

\section{Introdução}

A presente pesquisa geográfica faz uma análise das relações entre sociedade e natureza. Para tanto, foi incorporada nela a análise geossistêmica, que permite uma melhor compreensão dos elementos que compõem a paisagem geográfica. A Geografia, dentre suas diversas ramificações, realiza um estudo mais abrangente da relação do homem com o ambiente, ao analisar a apropriação do espaço e sua modificação pelas ações antrópicas. Esta alteração é manifestada por meio da paisagem, que, enquanto categoria geográfica, conforme Bertrand (1968), é o resultado da combinação dinâmica e instável dos elementos naturais e antrópicos que interagem dialeticamente, fazendo da paisagem um conjunto único em contínua evolução. 
A construção de reservatórios de usinas hidrelétricas é a principal fonte para geração de energia elétrica no Brasil. Este tipo de empreendimento hidráulico fez com que surgisse grande quantidade de ecossistemas lacustres artificiais, o que resultou em alterações hidrológicas, atmosféricas e biológicas, devido aos impactos ambientais ocorridos durante e após a construção dos mesmos e em decorrência das alterações no modelo de uso e ocupação das bacias hidrográficas (ESTEVES, 1998; CETESB, 2016; SILVA et al., 2017).

São indiscutíveis as importâncias e os papéis que desempenham os empreendimentos hidráulicos, seja para abastecimento, como irrigação, ou para a geração de energia elétrica. No entanto, este tipo de empreendimento altera toda a dinâmica fluvial do curso d'água, e altera o transporte dos sedimentos, que são depositados em maior proporção nos reservatórios, e, com eles, os metais potencialmente tóxicos (MPT), de origem natural ou antrópica (ABRID et al., 2014; GAIDOUMI et al., 2019; SOJKA et al,. 2019).

Historicamente, os MPTs são relacionados à Geoquímica da Paisagem, linha de pesquisa que deriva da Escola Russa do século XX, desenvolvida a partir das ideias de Dokuchaev. A primeira definição de Geoquímica da Paisagem é de Polynov. Polynov começou o estudo da paisagem com base nos estudos de Dokuchaev, que introduziu uma abordagem sistemática a partir da noção de complexo natural territorial, ou seja, os pressupostos da pedologia (FORTESCUE, 1992).

No Brasil, não existem muitos estudos na área de Geografia Física em relação à linha de pesquisa de MPT em sedimentos. A Geografia brasileira tem explorado o termo MPT em relação aos estudos de solos, como nos trabalhos desenvolvidos por Boulet et al. (2016), Nakashima et al. (2017) e Santos e Confessor (2020). A maioria dos estudos (práticos e conceituais) fundamenta-se no conceito de Geossistema definido por Sotchava ou Bertrand, levando em consideração a formação pedológica e os litotipos existentes em uma área de estudo, desconsiderando os elementos químicos, enquanto que os estudos de paisagem são focados nas perspectivas de análise morfopedológica, fisiográfica, geoconservacionista e de geodiversidade (CAVALCANTI; CORRÊA; ARAÚJO FILHO, 2010; DANTAS et al., 2015; CAVALCANTI; CORRÊA, 2016).

No intuito de compreender a influência do uso da terra nos sedimentos para explicar o nível de contaminação do ambiente, pode-se citar como exemplo as pesquisas desenvolvidas por Korobova et al. (1997) na bacia do rio Allier (França), por Licth et al. (2006) e Licth e Binttencourt (2013) para o estado do Paraná e a pesquisa de Yakovlev et al. (2020) para o distrito industrial de Severodvinsk (Noroeste da Rússia), que utilizaram as técnicas de gamaespectrometria e ICP.

Os MPT mais perigosos ambientalmente incluem Cromo $(\mathrm{Cr})$, Níquel $(\mathrm{Ni})$, Cobre $(\mathrm{Cu})$, Zinco $(\mathrm{Zn})$, Cádmio $(\mathrm{Cd})$, Chumbo $(\mathrm{Pb})$, Mercúrio $(\mathrm{Hg})$, e a transferência desses elementos para os organismos aquáticos e terrestres tem implicações importantes para a biodiversidade (POLETO e MERTEN, 2008; GAIDOUMI $e t$ al., 2019; ALI et al., 2019).

Segundo Cesar et al. (2011), Trindade et al. (2012) e CETESB (2016), os MPT presentes nos sedimentos podem ser de origem natural, conforme os minerais que compõem as rochas, ou de origem antrópica, como por exemplo o $\mathrm{Cu}, \mathrm{Zi}$ e $\mathrm{Ni}$ existentes nos agrotóxicos pois são considerados micronutrientes essenciais, sendo bastante utilizados nas atividades agropastoris.

A maioria dos fertilizantes utilizados na agricultura e pecuária contém diversos tipos de MPT, alguns considerados micronutrientes importantes para as atividades agropastoris. Porém, com a acumulação, passam a ser tóxicos, e com o processo de lixiviação do solo, causado pelas precipitações, são transportados para os corpos hídricos. Assim sendo, a qualidade da água e dos sedimentos é determinada em função do modelo de uso e cobertura da terra da bacia hidrográfica, sendo constatado que teores de metais são, muitas vezes, oriundos de atividades antropogênicas e podem causar efeitos adversos à biota (FRANZ et al., 2013; COSTA et al., 2015; BRAGA et al., 2018).

Os sedimentos têm grande importância na avaliação da contaminação e poluição dos ecossistemas aquáticos. Para avaliar a qualidade dos sedimentos em reservatórios, diversos pesquisadores têm utilizado análises estatísticas, modelos, resoluções e normas, com a finalidade de explicar os problemas ambientais vigentes em reservatórios (POMPÊO et al., 2013; SILVA et al., 2017; SOJKA et al., 2019). 
O Conselho Nacional do Meio Ambiente (CONAMA), no uso das atribuições que the confere a Resolução 454/2012, estabeleceu os critérios básicos, as diretrizes gerais e os procedimentos referenciais para o gerenciamento do material a ser dragado em águas sob jurisdição nacional, que permitem avaliar qualitativamente os sedimentos, classificando-os em Nível I - limiar abaixo do qual há menor probabilidade de efeitos adversos à biota, e Nível II - limiar acima do qual há maior probabilidade de efeitos adversos à biota (FROHLICH et al., 2015; MARTINS et al., 2017; BRAGA et al., 2018)

Outro modelo utilizado por diversos pesquisadores para avaliar o nível de poluição dos sedimentos é o índice de Geoacumulação proposto por Müller (1969), que varia entre "Praticamente não poluído" à "Extremamente poluído" (HORTELLANI et al., 2013; FRANKLIN et al., 2016; KIM et al., 2020).

A importância das pesquisas destacadas anteriormente deve-se à compreensão do estudo da paisagem por intermédio da concentração e qualidade dos sedimentos, em razão de os MPT serem oriundos dos eventos naturais e antrópicos ocorridos em bacias hidrográficas, pois, a qualidade dos sedimentos representa o reflexo dos processos intempéricos e morfopedogenéticos, além dos impactos ocasionados pelas atividades humanas sobre as bacias hidrográficas e a biota existente (MOORE; SUTHERLAND, 1981;STEVANOVIC et al., 2018).

Com base nos pressupostos, a presente pesquisa teve como objetivo avaliar a qualidade dos sedimentos de fundo do reservatório da UHE Foz do Rio Claro (GO), bem como verificar se os mesmos se encontravam dentro dos padrões do ordenamento jurídico de forma a determinar os riscos potenciais da presença desses MPT no reservatório.

\section{Materiais e métodos}

\subsection{Localização e caracterização da área de estudos}

O reservatório da UHE Foz do Rio Claro (Figura 1) está localizado na Bacia hidrográfica do rio Claro, entre os municípios de São Simão e Caçu, no Estado de Goiás, ocupando uma área de aproximadamente 7,69 $\mathrm{km}^{2}$, com tempo de residência de 4,9 dias. A UHE Foz do Rio Claro entrou em funcionamento em janeiro de 2010, e foi construída com a finalidade principal de gerar energia elétrica com potencial energético de 64,8 MW(CONSILIU MEIO AMBIENTE e PROJETOS, 2007; NOGUEIRA et al., 2015).

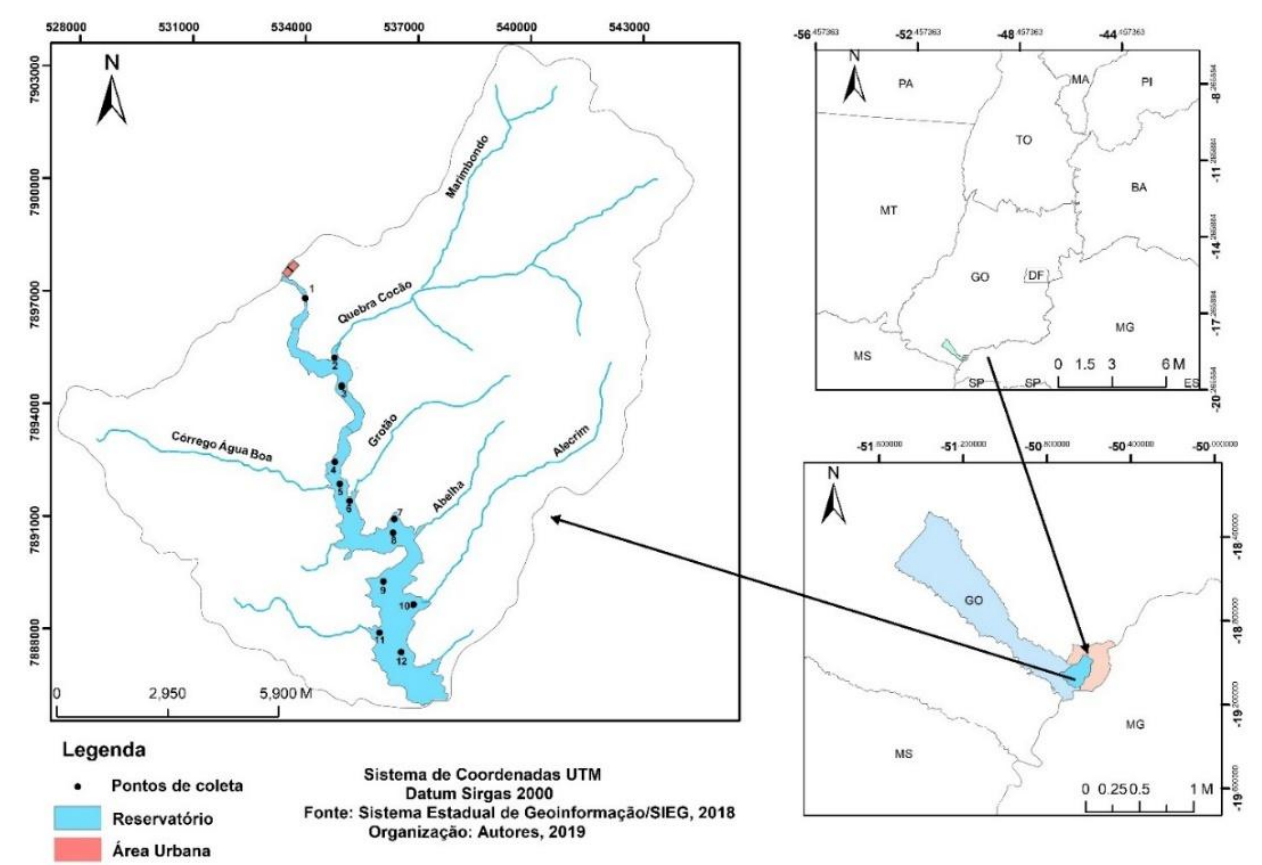

Figura 1 - Localização da área de realização da pesquisa. Organização: Autores.

Link para pontos no google Earth. https://earth.google.com/web/@-19.06851192,-

50.66064411,372.49972721a,12739.71521986d,30y,0h,0t,0r/data=MicKJQojCiExZXI0c280ZUJUVzVDek12UHlaRGlqcGVYVV 9kR3FXLXE?utm_source=earth7\&utm_campaign=vine\&hl=pt-BR) 
A bacia hidrográfica resulta da integração dos elementos físicos, biológicos e antrópicos que ocorrem como mosaicos na paisagem, sendo uma unidade considerada para o planejamento territorial e básica para planejamento e gestão dos recursos hídricos.

A escolha desse reservatório para o desenvolvimento da presente pesquisa deve-se ao processo de uso e ocupação das terras da bacia do rio Claro, com a predominância de atividades agropecuárias, que se intensificaram a partir do ano de 1970, e mais recentemente pela produção de cana-de-açúcar e pela construção de diversos empreendimentos hidrelétricos.

A área de influência direta do reservatório, geologicamente, situa-se na Bacia Sedimentar do Paraná e apresenta dois grandes grupos litoestratigráficos, os basaltos da Formação Serra Geral do Grupo São Bento e os arenitos da Formação Vale do Rio do Peixe do Grupo Bauru (SIEG, 2011). Pedologicamente, tem-se na bacia a predominância de Latossolos Vermelho distroférrico, Latossolos Vermelho distrófico e Neossolo litólico, com declividades que vai de plana a suave ondulada (NOGUEIRA et al., 2015).

O clima da região é característico do Cerrado brasileiro, com a ocorrência de um período chuvoso, que se estende de outubro a abril, com maior concentração de chuvas, que variam entre 80 a $500 \mathrm{~mm}$ mensais, e um período menos chuvoso, de maio a setembro, com concentração de chuvas entre 0 a $80 \mathrm{~mm}$, classificado como Awa, tropical de savana. A média anual da precipitação varia de 1400 a 1750 mm (LOPES; MARIANO, 2018).

Quanto ao uso da terra, a principal atividade é a agropastoril, com predomínio para gado de corte, predominado as culturas de cana-de-açúcar, milho e soja (QUEIROZ JUNIOR et al., 2014; NOGUEIRA et al., 2015).

\subsection{Procedimento metodológico}

Foram selecionados 10 pontos para coleta de sedimentos na área de estudo (Figura 1). Os pontos de amostragem foram pré-determinados por meio de imagens de satélite, de modo a abranger setores distintos do lago do reservatório.

A coleta dos sedimentos para análise de metais pesados foi realizada no dia 02 de agosto de 2015, período com baixos índices de chuvas para o Cerrado brasileiro.

Para a amostragem dos sedimentos, foi utilizado o coletor de sedimentos de fundo tipo Kajac, conforme descrito em Braga et al. (2018). As amostras foram secas em temperatura ambiente por um período de 30 dias, seguindo o protocolo descrito por Filizola (2006), e depois foram retiradas alíquotas de 50 gramas de cada uma delas, as quais foram enviadas para o Laboratório Exata, no município de Jataí (GO), para as análises dos metais potencialmente tóxicos por Espectrometria óptica de emissão atômica com plasma indutivamente acoplado - ICP OES (marca PERKIN ELMER, modelo OPTIMA 8300 DV), seguindo o método da USEPA - 3051 (2007).

Após secagem, alíquotas de aproximadamente 0,50 gramas foram adicionadas em tubos de digestão, seguido da adição de aproximadamente, $9 \mathrm{~mL}$ de $\mathrm{HNO}_{3}$ e $3 \mathrm{~mL}$ de $\mathrm{HCl}$ subdestilado (duplicatas), respectivamente (USEPA, 2007).

A digestão das amostras foi realizada em forno micro-ondas (marca Ethos UP, Millestone) por um período de 30 minutos. Após resfriadas, as amostras foram filtradas, transferidas para balão volumétrico de $50 \mathrm{~mL}$ e foi adicionada água ultrapura até completar o volume. Posteriormente, as amostras foram mantidas em refrigeração em temperatura de $4{ }^{\circ} \mathrm{C}$ para depois ser realizada análise química.

A digestão da matéria orgânica (MO) foi realizada de acordo com a proposta de Jackson (1967). Foi utilizado $1,0 \mathrm{~g}$ da massa triturada. A massa foi queimada em forno de mufla numa temperatura de $500^{\circ} \mathrm{C}$ por 4 horas e, em seguida, foi resfriada em um dessecador, em ambiente livre de umidade. O cálculo da MO perdida por ignição se dá por meio da diferença de massa (JACKSON, 1967) de acordo com a equação I. 
Onde:

Ps $=$ peso seco total da amostra (partículas minerais $+\mathrm{MO})$

$\mathrm{Pm}=$ peso seco da amostra queimada em mufla (partículas minerais)

As análises qualitativas dos sedimentos foram realizadas conforme valores determinados pela Resolução CONAMA $n^{\circ}$ 454/2012, a qual estabelece diretrizes para avaliar a qualidade e quantidade de MPT permitidos, para que não sejam prejudiciais ao ambiente e ao ser humano, estabelecendo limites, conforme o Tabela 1.

Tabela 1: Valores orientadores de $\mathrm{Ni}, \mathrm{Cd}, \mathrm{Pb}, \mathrm{Cu}$ e $\mathrm{Zn}$ presentes nos sedimentos conforme a resolução CONAMA n. 454/2012.

\begin{tabular}{lccccc}
\hline $\begin{array}{l}\text { Nível de } \\
\text { classificação }\end{array}$ & \multicolumn{5}{c}{ Metais potencialmente tóxicos } \\
\hline & $\mathbf{N i}$ & $\mathbf{C d}$ & $\mathbf{P b}$ & $\mathbf{C u}$ & $\mathbf{Z n}$ \\
Nível I (mg/kg) & 18,0 & 0,6 & 35,0 & 35,7 & 123,0 \\
Nível II (mg/kg) & 35,9 & 3,5 & 91,3 & 197,0 & 315,0 \\
\hline
\end{tabular}

Fonte: CONAMA n ${ }^{\circ} 454 / 2012$. Adaptado pelos autores

O nível de poluição dos sedimentos foi obtido por intermédio do Índice de Geoacumulação (Igeo) Tabela 2 segundo a proposta de Müller (1969).

Para tanto, aplica-se a Equação 2. Os valores propostos para o enquadramento do Igeo encontram-se na Tabela 2.

$$
\mathrm{IGEO}=\log _{2} \mathrm{Cn} /\left(1,5 \times \mathrm{C}_{\mathrm{Bn}}\right)(16)
$$

Em que:

Cn: concentração do elemento na fração fina do sedimento a ser classificado;

$\mathrm{C}_{\mathrm{Bn}}$ : é a concentração média de "background" geoquímico do elemento;

1,5: fator de correção para possíveis variações do "background" causado por diferenças litológicas.

Tabela 2: Intensidade de poluição conforme o índice de Geoacumulação (Igeo)

\begin{tabular}{lcc}
\hline \multicolumn{1}{c}{ Descrição da qualidade dos sedimentos } & Classe $($ Igeo $)$ & Valor do índice \\
\hline Extremamente poluído & 6 & Igeo $>5$ \\
Fortemente à extremamente poluído & 5 & $4<$ Igeo $<5$ \\
Fortemente poluído & 4 & $3<$ Igeo $<4$ \\
Moderadamente à fortemente poluído & 3 & $2<$ Igeo $<3$ \\
Moderadamente poluído & 2 & $1<$ Igeo $<2$ \\
Não poluído a moderado poluído & 1 & $0<$ Igeo $<1$ \\
Praticamente não poluído & 0 & Igeo $\leq 0$ \\
\hline
\end{tabular}

Fonte: Müller (1969). Adaptado pelos autores.

Os valores de referência (backgrounds) regionais para o Igeo foram estabelecidos com base na menor concentração natural do elemento no ambiente, conforme Nascimento et al. (2018). Os valores estabelecidos para o background estão apresentados na Tabela 3. 
Tabela 3: Valor de background utilizado para os cálculos do Igeo nos sedimentos

\begin{tabular}{lccccc}
\hline Background * & $\mathbf{C u}$ & $\mathbf{Z i}$ & $\mathbf{C a}$ & $\mathbf{P b}$ & $\mathbf{N i}$ \\
\hline Índice de Geoacumulação & 54,43 & 54,3 & 4,92 & 17,22 & 9,07 \\
\hline
\end{tabular}

Organização: Adaptado pelos autores.

A análise granulométrica dos sedimentos foi realizada de acordo com a proposta da Embrapa (1997). Os sedimentos coletados foram acondicionados em bandeja de alumínio e deixados em estufa a temperatura de $105^{\circ} \mathrm{C}$ por aproximadamente 48 horas. Após esse período, as amostras foram destorroadas e passadas em peneira de malha de $2 \mathrm{~mm}$. A areia foi separada por peneiramento. A fração argila total (diâmetro menor que $0,002 \mathrm{~mm}$ ) foi determinada por pipetagem, respeitando a Lei de Stokes, e a fração silte (diâmetro entre 0,05 a $0,002 \mathrm{~mm}$ ) foi calculada pela diferença entre a soma das frações areia e argila total.

\section{Resultados e discussão}

Os resultados obtidos para as amostras coletadas em campo para os sedimentos quanto ao Potencial Hidrogeniônico $(\mathrm{pH})$, Capacidade de Troca Catiônica (CTC), teores de matéria orgânica (MO), frações granulométricas e concentração de metais potencialmente tóxicos (MPT) e Níveis determinados pela Resolução CONAMA podem ser verificados no Tabela 4.

Tabela 4: Concentração dos metais nos sedimentos da UHE Foz do Rio Claro

\begin{tabular}{|c|c|c|c|c|c|c|c|c|c|c|c|}
\hline & pH & $\begin{array}{c}\text { CTC } \\
\mathrm{cmolc} / \mathrm{kg}\end{array}$ & $\begin{array}{c}\text { MO } \\
\%\end{array}$ & $\underset{\%}{\operatorname{Argila}}$ & Silte \% & $\underset{\%}{\text { Areia }}$ & $\begin{array}{c}\mathrm{Pb} \\
\mathrm{mg} / \mathrm{kg}\end{array}$ & $\begin{array}{c}\mathrm{Zn} \\
\mathrm{mg} / \mathrm{kg}\end{array}$ & $\begin{array}{c}\mathrm{Ni} \\
\mathrm{mg} / \mathrm{kg}\end{array}$ & $\begin{array}{c}\mathrm{Cu} \\
\mathrm{mg} / \mathrm{kg}\end{array}$ & $\begin{array}{c}\mathrm{Cd} \\
\mathrm{mg} / \mathrm{kg}\end{array}$ \\
\hline P1 & 5,7 & 09,3 & 07,9 & 25,9 & 62,4 & 11,7 & 11,6 & 54,2 & 21,2 & 66,9 & 09,7 \\
\hline $\mathbf{P 2}$ & 5,0 & 24,8 & 07,4 & 25,6 & 64,1 & 10,3 & 13,6 & 61,2 & 26,7 & 78,9 & 11,2 \\
\hline P3 & 5,2 & 30,5 & 10,8 & 26,9 & 48 & 25,1 & 15,6 & 61,9 & 22,8 & $\begin{array}{l}83,0 \\
126,\end{array}$ & 12,3 \\
\hline P4 & 4,6 & 14,5 & 06,1 & 28 & 65,1 & 6,9 & 17,2 & 67,6 & 26,3 & 1 & 13,8 \\
\hline P5 & 5,9 & 21,5 & 05,4 & 26,7 & 62,8 & 10,5 & 13,0 & 46,0 & 15,2 & 74,3 & 07,4 \\
\hline P6 & 5,0 & 17,6 & 07,7 & 27,7 & 42,2 & 30,1 & 05,6 & 35,7 & 6,6 & 41,9 & 06,3 \\
\hline P7 & 5,2 & 23,9 & 12,0 & 27,1 & 45,7 & 27,2 & 14,7 & 56,2 & 20,7 & $\begin{array}{l}76,6 \\
118,\end{array}$ & 12,3 \\
\hline P8 & 5,5 & 21,7 & 07,3 & 27,7 & 49,1 & 23,2 & 17,1 & $\begin{array}{l}94,3 \\
104,\end{array}$ & 28,1 & $\begin{array}{l}6 \\
111,\end{array}$ & 16,7 \\
\hline P9 & 6,1 & 10,3 & 03,0 & 25,1 & 24,6 & 50,3 & 12,3 & & 12,3 & $\begin{array}{l}1 \\
205,\end{array}$ & 16,7 \\
\hline $\begin{array}{l}\text { P10 } \\
\text { Níve }\end{array}$ & 6,4 & 21,4 & 11,5 & 24,9 & 61,7 & 13,4 & 08,1 & $\begin{array}{l}3 \\
123,\end{array}$ & 17,2 & 3 & 25,5 \\
\hline $\begin{array}{l}\text { l I } \\
\text { Níve }\end{array}$ & - & - & - & - & - & - & 35,0 & $\begin{array}{l}0 \\
315,\end{array}$ & 18,0 & $\begin{array}{l}35,7 \\
197,\end{array}$ & 0,6 \\
\hline I II & - & - & - & - & - & - & 91,3 & 0 & 35,9 & 0 & 3,5 \\
\hline
\end{tabular}

$\mathrm{O} \mathrm{pH}$ dos sedimentos, para o período analisado, indica um ambiente ácido. Os valores variaram entre 04,62 a 06,44, fato que pode ser associado aos tipos de solos da área de influência. Os Latossolos Vermelho distrófico apresentam saturação por bases < 50\% na maior parte dos primeiros $100 \mathrm{~cm}$ do horizonte B, enquanto o Latossolo Vermelho distroférrico apresenta saturação por bases $\geq 50 \%$ e contém teores elevados de $\mathrm{Fe}_{2} \mathrm{O}_{3}, \mathrm{MnO}$ e $\mathrm{TiO}_{2}$ (EMBRAPA, 2018).

Os solos do Cerrado são ácidos, com baixa disponibilidade de nitrogênio $(\mathrm{N})$, fósforo $(\mathrm{P})$, potássio $(\mathrm{K})$, cálcio $(\mathrm{Ca})$, magnésio $(\mathrm{Mg})$, zinco $(\mathrm{Zn})$, boro $(\mathrm{B})$ e cobre $(\mathrm{Cu})$, sendo considerado pobre em nutrientes e alguns micronutrientes para a maioria das plantas, apresentando sérias limitações para a produção de alimentos, mas, com o uso correto de agroquímicos, são altamente produtivos e adequados para o 
desenvolvimento das atividades agropastoris (MARQUES et al., 2004; EMBRAPA, 2018; RAMOS et al., 2020).

A utilização de agroquímicos de forma descontrolada causa diversos impactos ao ambiente, como a contaminação dos solos e sedimentos, o que torna urgentes e imprescindíeis medidas de proteção e preservação do ambiente, sendo necessário conhecer a dinâmica dos MPT, que são regidos por uma série de reações químicas (RAMALHO et al., 2000; MATTOS et al., 2016; MARTINAZZO et al., 2020).

A menor concentração de MO foi verificada para o Ponto 09 e a maior concentração foi verificada no ponto 10. Na composição da matéria orgânica estão presentes inúmeros grupos funcionais, especialmente os grupos fenólicos e carboxílicos. Esses grupos podem interagir com metais via ligações iônicas, bem como por reações de complexação. Os teores encontrados de MO podem estar associados à contribuição de material alóctone, que pode ser depositado no reservatório ao longo de anos, tendo a matéria orgânica possibilidade de carrear consigo consideráveis concentrações de nutrientes. Conforme Silva et al. (2017), a complexação poderá manter o metal em solução, favorecer o transporte ou torná-lo indisponível para o meio, interações estas que, dependendo do $\mathrm{pH}$ do meio, têm potencial para diminuir sua toxicidade e ou mobilidade no meio, o que, consequentemente, consegue diminuir sua mobilidade nos sedimentos, especialmente em $\mathrm{pH}$ ácido.

Os valores de CTC variaram de 9,36 (ponto 1) a 30,56 cmolc / $\mathrm{kg}$ (ponto 3), demonstrando que nesse reservatório ocorre uma alta capacidade de permuta de cátions dos sedimentos com o meio, trocando íons efetivamente e retendo uma maior quantidade de metais. Isto demonstra que quanto maior for a concentração de material silte-argiloso e de MO, maior será a possibilidade para se reter cátions. Por outro lado, quanto menor for a concentração de material silte-argiloso, menor será a possibilidade de se reter cátions. Esse resultado também foi verificado na pesquisa desenvolvida por Martins et al. (2017), no estudo de metais potencialmente tóxicos no lago Bonsucesso, em Jataí-GO.

Em relação ao elemento Chumbo, a concentração detectada nos sedimentos apresenta valores inferiores ao limite do nível I da Resolução CONAMA n ${ }^{\circ}$ 454/2012 (Figura 2A), sendo os sedimentos classificados qualitativamente conforme o Igeo (Figura $2 \mathbf{B}$ ) entre as classes 1 e 5.

A menor concentração (Ponto 6) foi de $5,61 \mathrm{mg} / \mathrm{kg}$ e a maior concentração de $\mathrm{Pb}$ (ponto 4) foi de 17,18 $\mathrm{mg} / \mathrm{kg}$, sendo o nível de poluição considerado qualitativamente entre Moderadamente poluído e Fortemente à extremamente poluído.

A alta concentração de areia $(30,1 \%)$ detectada no ponto 6 pode ser a responsável pela menor concentração de $\mathrm{Pb}$, pois esse tipo de sedimento não têm a capacidade de reter e concentrar MPT. Nesse caso, destacam-se os compostos argilominerais, os óxidos hidróxidos de ferro e manganês e as substâncias húmicas e coloides como os que possuem maior capacidade de reter metais (GOMES et al., 2010).

As concentrações de areia no ponto de amostragem 6, podem ser associadas à antiga área de pastagem degradada existente nesse ambiente antes do processo de enchimento do lago. Já a alta concentração de MO pode ser relacionada a não retirada da vegetação da antiga área de APP que foi inundada próxima a esse ponto de amostragem.

Os valores de $\mathrm{Pb}$ nos sedimentos do reservatório Foz do Rio Claro apresentam valores próximos aos estudos realizados por Sojka et al. (2019), em seis reservatórios na Polônia. Os autores detectaram valores médio que variaram de $2,6 \mathrm{mg} / \mathrm{kg}$ a $17,6 \mathrm{mg} / \mathrm{kg}$. No estudo realizado por Nascimento et al. (2018), para sedimentos em doze pontos distintos da bacia hidrográfica do Rio do Peixe, os elevados resultados do $\mathrm{Pb}$ foram associados ao Distrito Industrial de Itabira, fato distinto aos do reservatório de Foz do Rio Claro que não possui distrito industrial na área de influência, mas, sofre com o lançamento de dejetos urbanos do distrito de Itaguaçu/GO para o corpo hídrico, fato também detectado por Belo et al. (2010) para os sedimentos superficiais das praias do lago de Itaipu. 
A)

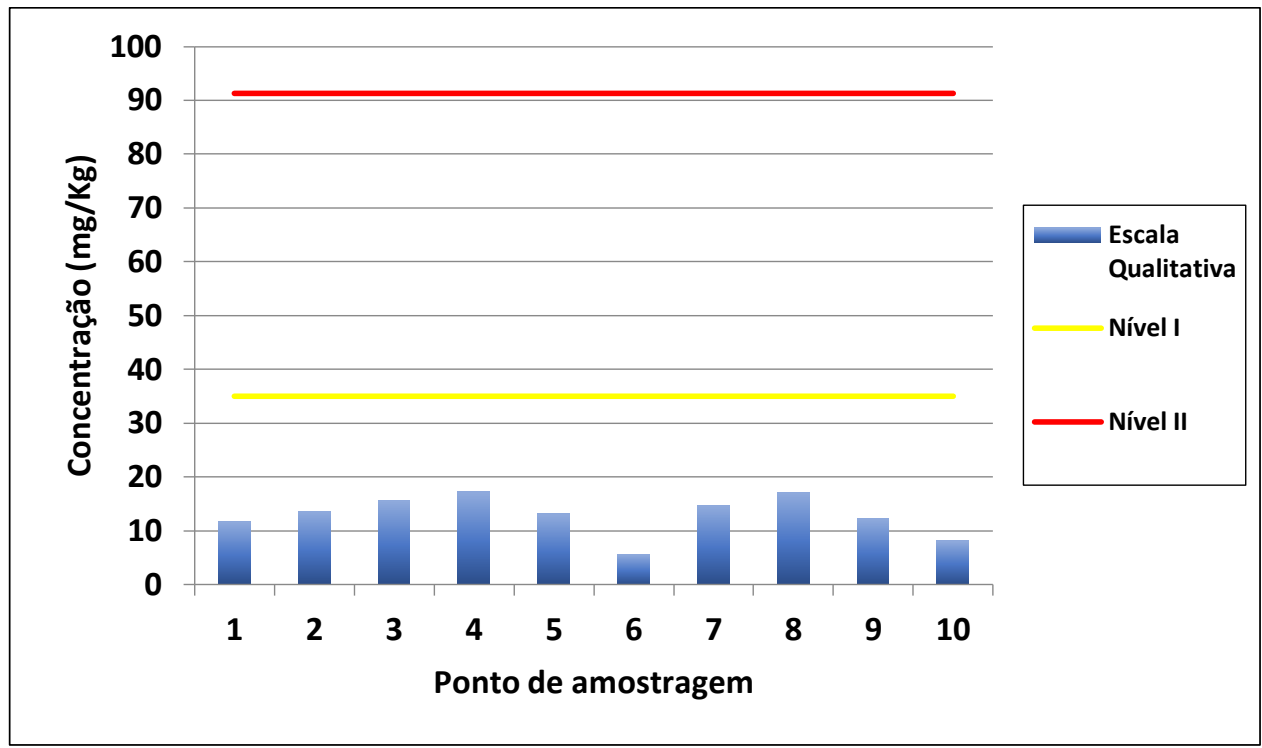

B)

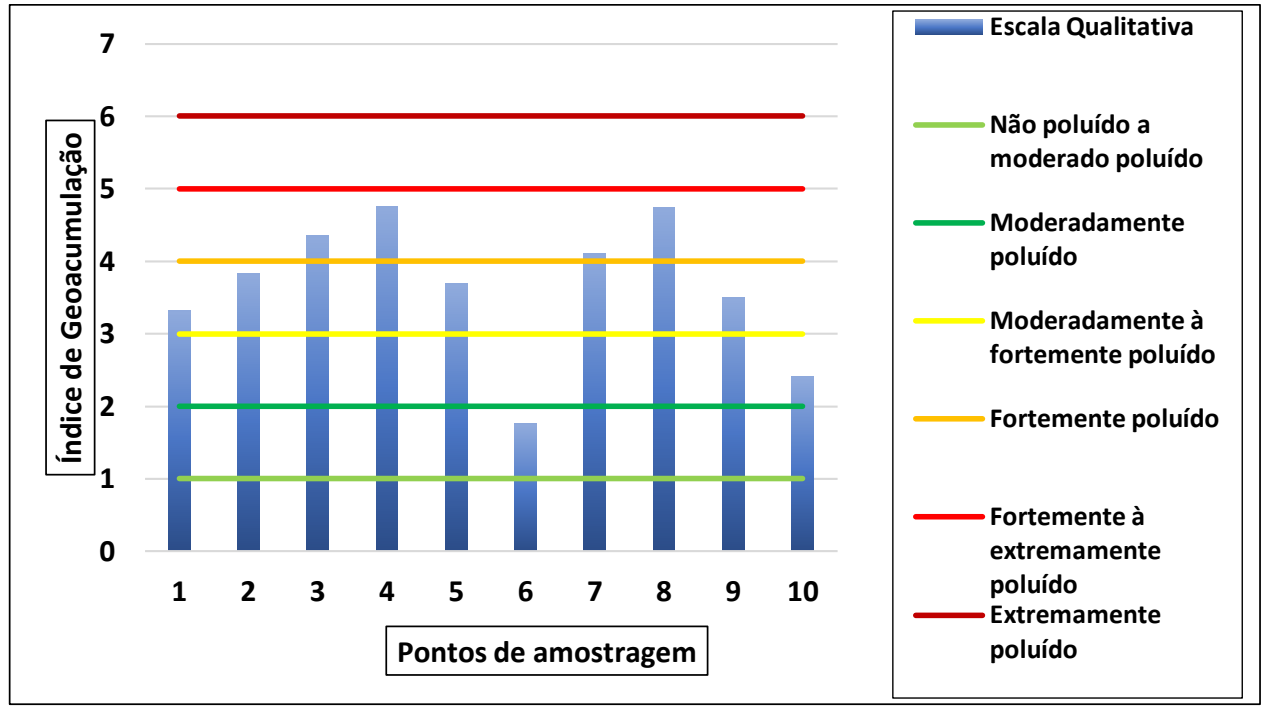

Figura 2: Concentração de $\mathrm{Pb}$ verificada nos sedimentos depositados no reservatório.

\section{Organização: Autores}

Conforme o Igeo, os sedimentos nos pontos 4 e 8 foram classificados como Fortemente à Extremamente poluídos. A alta concentração de poluição nesses pontos pode estar relacionada à forte antropização da bacia e ao modelo de uso da terra, baseado na pecuária e agricultura.

O conhecimento da concentração de $\mathrm{Pb}$ e outros metais, a partir dos elementos litológicos, pedológicos e o modelo de uso da terra em uma bacia hidrográfica, é essencial no diagnóstico da contaminação do sedimentos, visto que fertilizantes e pesticidas são importantes insumos utilizados na produção agropastoril no mundo e no Brasil; porém, muitos trabalhos têm demonstrado que, quando utilizados em grandes quantidades, fertilizantes fosfatados e compostos têm proporcionado a contaminação de ambientes lacustres (GOMES et al., 2010; CARDOSO-SILVA et al., 2017).

Quanto à concentração do $\mathrm{Zn}$ em nove pontos de amostragem, os valores enquadram-se na Resolução vigente para o nível I (Figura 3A). Quando aplicado o Igeo para o Zn (Figura 3B), os níveis de poluição indicam um ambiente entre as classes 2 e 6 , sendo os sedimentos classificados qualitativamente entre Moderadamente poluídos à Extremamente poluídos. 
A)

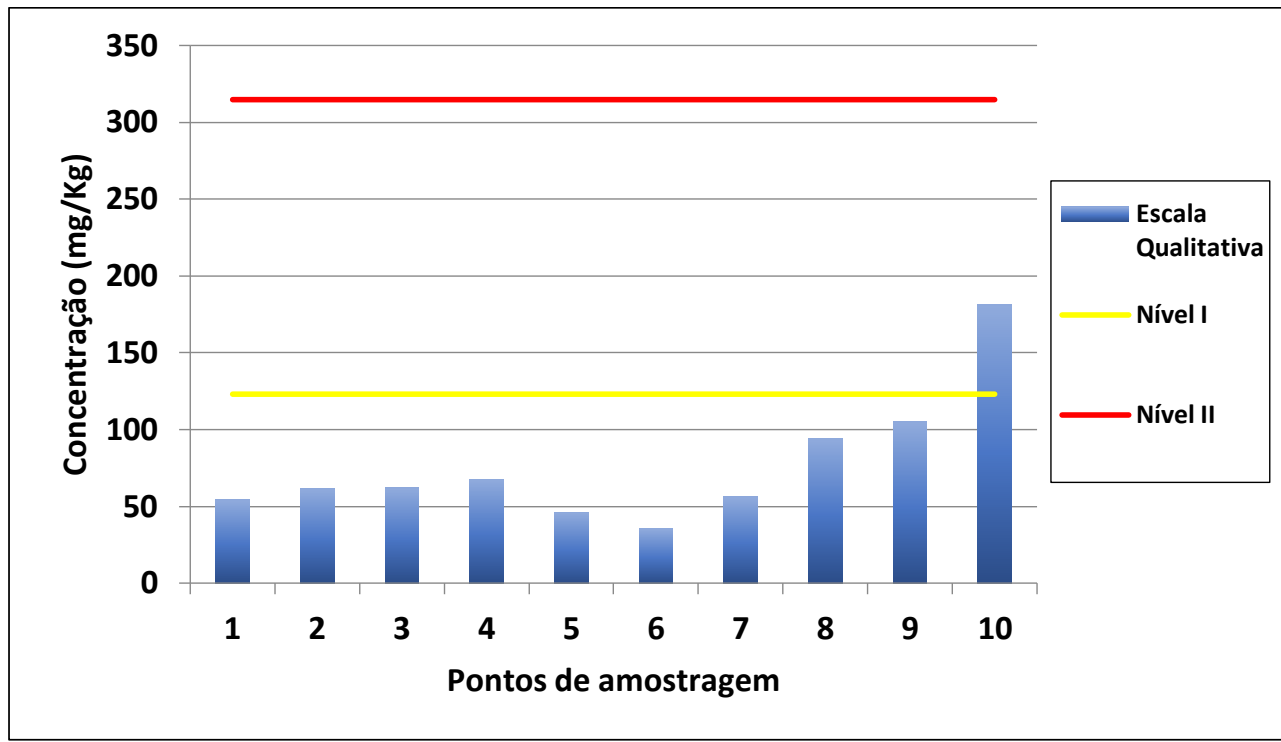

B)

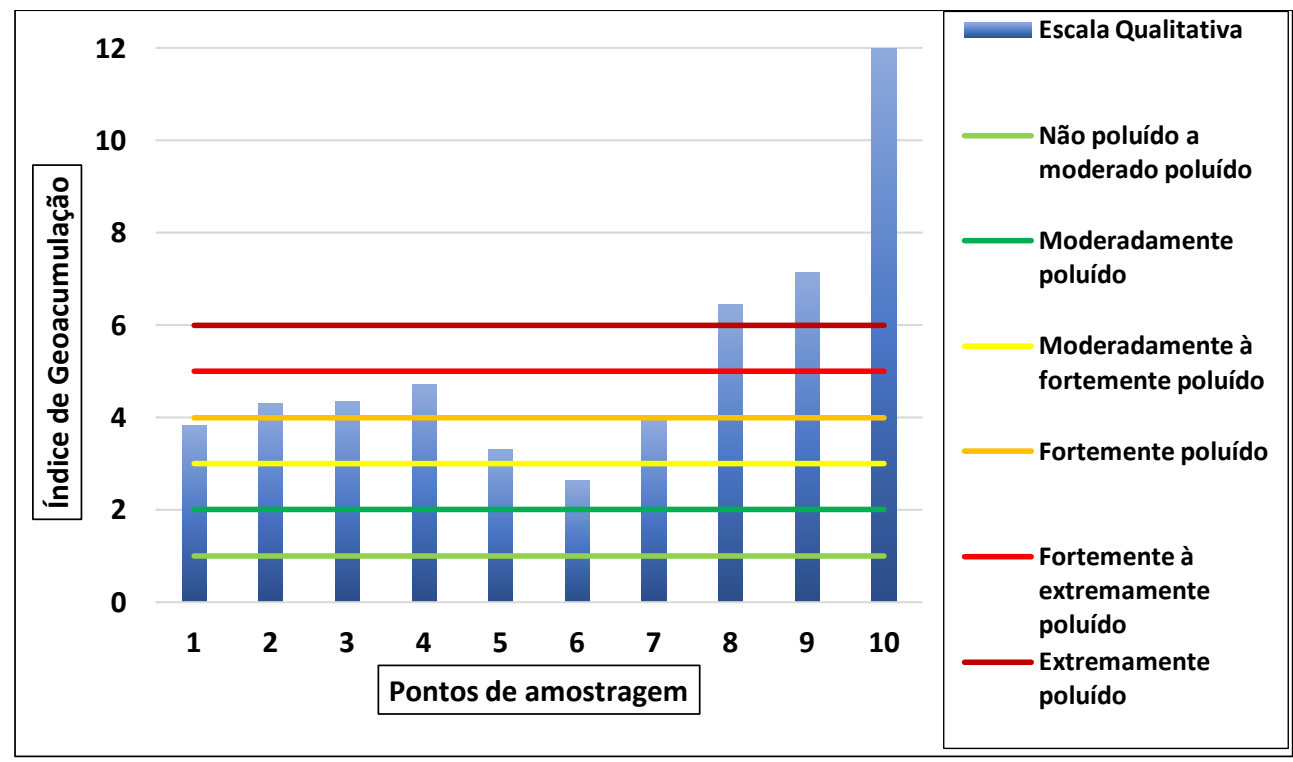

Figura 3: Concentração de $\mathrm{Zn}$ verificada nos sedimentos depositados no reservatório.

\section{Organização: Autores}

Ao se comparar os resultados obtidos para o $\mathrm{Zn}$ na presente pesquisa, em relação à Resolução Conama 454/2012, com os estudos realizado por Souza (2009) para o reservatório de Itá, por Copaja et al. (2016) para os reservatórios de Cogotí, Corrales, La Paloma e Recoleta no Chile, e por Silva et al. (2016) no Rio Monjolinho, não foram verificados valores considerados prejudiciais ao ambiente em 9 pontos de amostragem. Entretanto tais estudos demonstram as preocupações em nível de estudo de contaminações por metais potencialmente tóxicos, visto que os sedimentos contaminados podem ser prejudiciais aos recursos biológicos das águas superficiais e, indiretamente, à saúde humana (FU; WANG, 2011; DĄBROWSKA, 2016).

Os pontos de amostragem que apresentam o maior nível de poluição são o 8, 9 e 10. Eles enquadram-se como de grau 6, indicando qualitativamente que essas áreas de influência podem ser consideradas contaminadas, representando riscos ao ambiente. Esses pontos de amostragem localizam-se na área do reservatório mais próxima ao barramento, ambiente em que ocorre a deposição de materiais predominantemente silte-argilosos, devido à diminuição da velocidade de escoamento da água e maior tempo de residência que, conjuntamente com a CTC e MO, detêm a capacidade de reter e concentrar MPT devido aos compostos de argilominerais e as substâncias húmicas.

As concentrações de Ni nos sedimentos do reservatório, de acordo com Resolução CONAMA 454/2012, (Figura 4A), enquadram-se no nível I para os pontos $(05,06,09,10)$, enquanto que o restante das amostras 
avaliadas é classificado como de Nível II, podendo causar efeitos adversos à biota. Conforme o Igeo (Figura 4B) os sedimentos apresentam valores entre $1<$ igeo $<5$, sendo os mesmos classificados entre Moderadamente poluídos a fortemente à Extremamente poluído.

A)

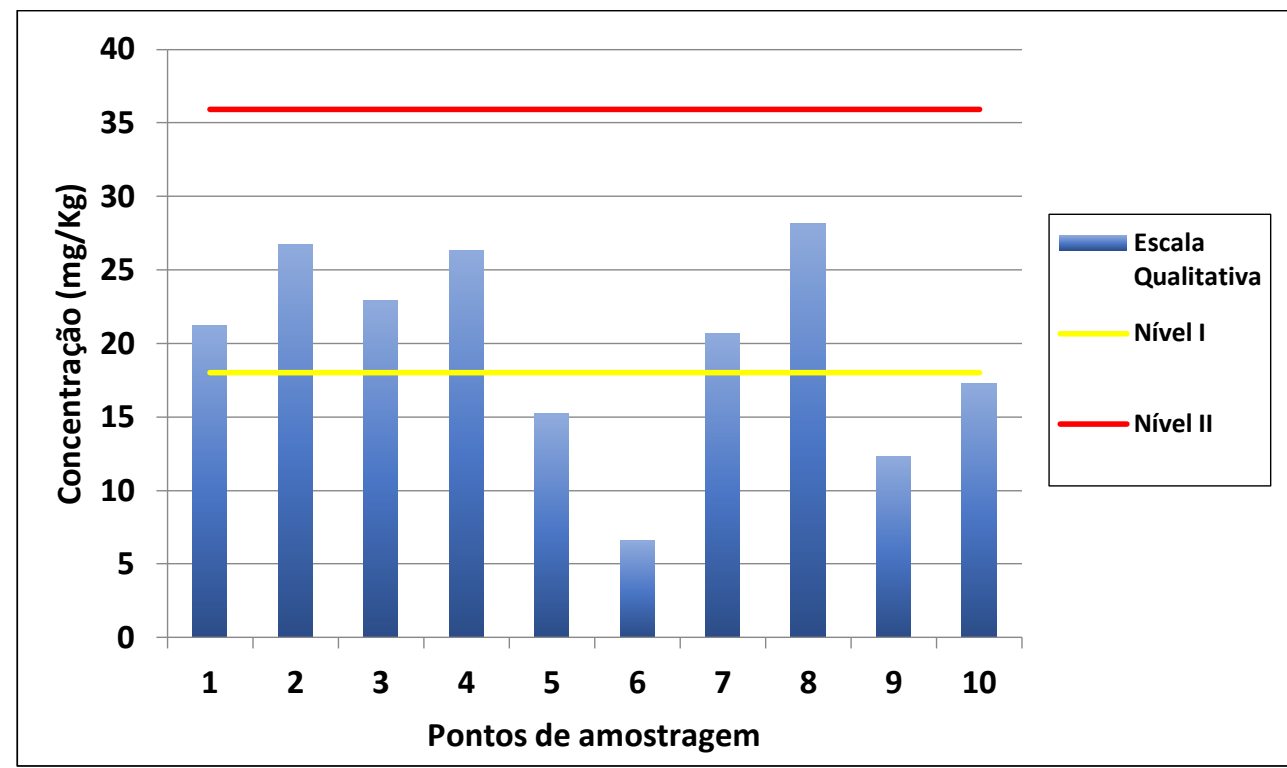

B)

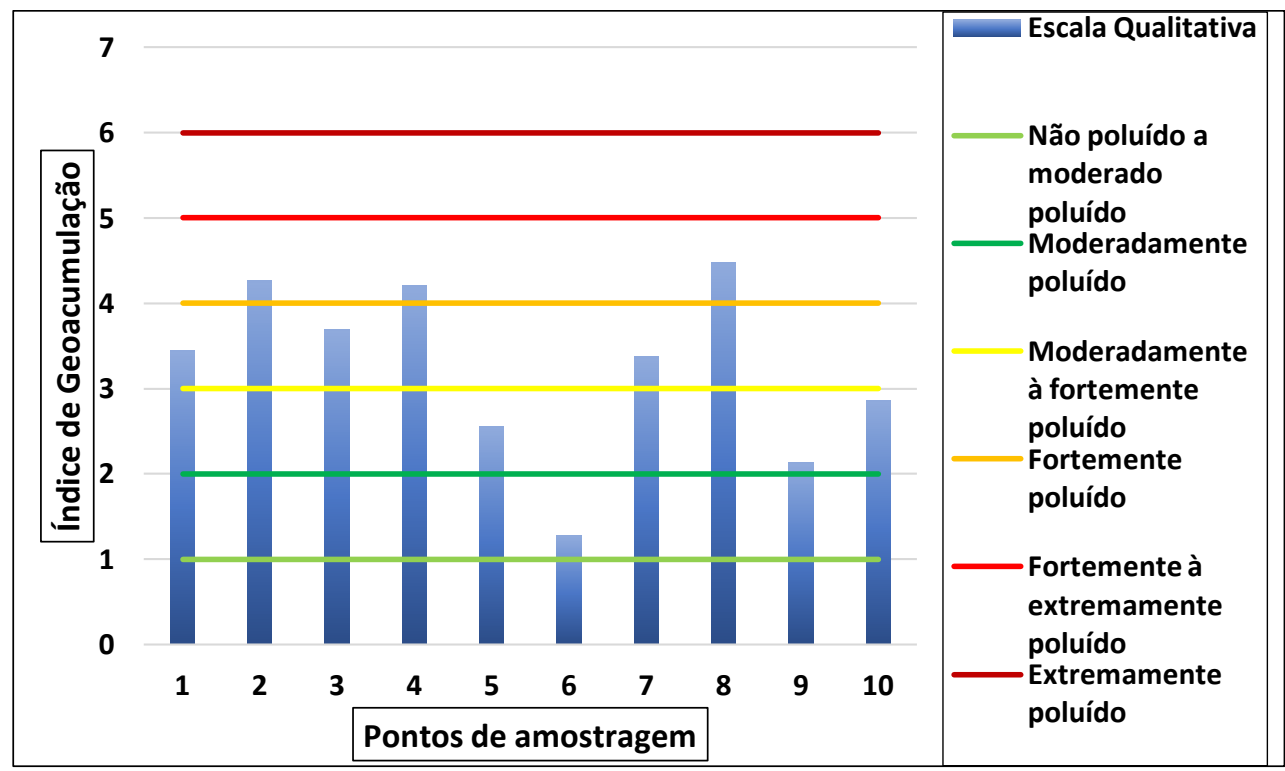

Figura 4: Concentração de Ni verificada nos sedimentos depositados no reservatório.

Organização: Autores

A maior concentração de $\mathrm{Ni}$ foi detectada no ponto de amostragem 08 , que apresenta um $\mathrm{pH}$ de 5,56 , CTC de 21,70 cmolc $/ \mathrm{kg}, 7,36 \%$ de MO, 23,30 de material arenoso e 76,70 \% de material silte-argiloso. A menor concentração foi detectada no ponto de amostragem 06 que apresenta um pH, CTC e material-silte argiloso com valores inferiores ao ponto de amostragem 08, demonstrando que quanto maior for a concentração de material arenoso, menor será a capacidade de digestão da MO.

A concentração detectada de Ni pode estar relacionada a processos de intemperismo das rochas basálticas da Formação Serra Geral, as quais têm potencial para serem depósitos de níquel (CPRM, 2006; BERGMANN et al., 2014). Outra hipótese verificada são os fertilizantes utilizados nas lavouras, que possuem em sua composição sulfato de níquel, pois não há informações sobre atividades de fusão e refino desse metal na área de estudo, fato também relatado por Santos et al. (2015) no estudo da bacia do rio Madeira, e Nascimento et al. (2018) no estudo dos sistemas fluviais do quadrilátero ferrífero. 
A possível influência de fontes antropogênicas em relação ao Ni nos sedimentos do reservatório também foi relatada nos estudos desenvolvido por An e Kampbell (2010), no lago Taxoma - EUA, e por Oliveira et al. (2018) para os sedimentos do lago Água Preta, no Pará (Brasil). Françoso, Oliveira e Ressel (2014) entretanto, relacionam as elevadas concentrações de Ni à possível falta ou baixa eficiência no tratamento de efluentes que são lançados no corpo d'água, o que pode justificar também a alta concentração do Ni nos pontos de amostragem 1,2,3 e 4, os quais conforme a distância, podem sofrer influência do distrito de Itaguaçu (GO), que tem seus efluentes urbanos lançados diretamente no curso d'água.

Apesar de o presente estudo diagnosticar que os sedimentos não apresentam concentrações acima do nível II da Resolução Conama, eles foram classificados como Fortemente poluídos, o que demonstra que é importante realizar uma análise contínua dos níveis de contaminação dos sedimentos, haja vista que os mesmos são capazes de se acumularem por longo tempo, podendo, com isso, aumentar o nível de contaminação, e as análises fornecem informações úteis para a gestão e planejamento territorial das bacias hidrográficas, visando à elaboração de uma normatização de uso da terra com vistas à conservação ambiental (MAZZILLI et al., 2011; RODRIGUEZ; SILVA, 2013).

Apesar de os valores do Ni terem variado entre $06,60 \mathrm{mg} / \mathrm{kg}$ e $20,69 \mathrm{mg} / \mathrm{kg}$, os níveis de poluição verificados, quando excedem os limites das diretrizes de qualidade dos sedimentos, são preocupantes, pois, a ingestão de alimentos/nutrientes contaminados com este metal pode causar efeitos adversos à biota (CETESB, 2005; DORIA et al., 2017).

De acordo com a Resolução CONAMA 454/12, os valores de referência para Cu em sedimentos variam de $35,7 \mathrm{mg} / \mathrm{kg}$ (Nível I) a $197 \mathrm{mg} / \mathrm{kg}$ (Nível II). A concentração de $\mathrm{Cu}$ verificada nos sedimentos do reservatório pode ser considerada elevada quando comparada à Resolução CONAMA (Figura 5 A), sendo classificada acima do nível I em 9 pontos de amostragem, e 1 ponto acima do nível II, podendo consequentemente causar efeitos adversos à biota.

Em relação ao nível de poluição por intermédio do índice de geoacumulação (Figura 5B), os sedimentos do reservatório foram classificados entre Moderadamente a fortemente poluído, à Extremamente poluído.

O Ponto de amostragem 10 foi o que apresentou a maior concentração e nível de poluição. Tal fato pode ser associado aos altos valores de CTC $(21,5 \mathrm{cmolc} / \mathrm{kg})$, MO (11,5\%) e alta concentração de material silteargiloso (86,5\%), pois, conforme Campbell et al. (1988), sedimentos com alto conteúdo de MO são fundamentais na ligação de poluentes orgânicos e metais, que são de grande relevância para a transferência dessas substâncias nos sistemas biológicos.

A menor concentração de $\mathrm{Cu}$, detectada no ponto de amostragem 6 , ocorre devido à maior concentração de material arenoso $(30,1 \%)$ e acidez do $\mathrm{pH}(5,0)$ que proporcionaram uma menor digestão da MO e menor capacidade de troca de cátions dos sedimentos com o meio.

Ao se comparar as concentrações de $\mathrm{Cu}$ do reservatório Foz do Rio Claro, com os dados de $\mathrm{Cu}$ do reservatório da UHE Caçu na pesquisa desenvolvida por Braga et al. (2018), verifica-se que em ambas as pesquisas as maiores concentrações de $\mathrm{Cu}$ ocorrem próximas à área do barramento, trecho do reservatório considerado como setor lago, local em que a velocidade de escoamento da água é fraca em relação aos outros setores do reservatório e o tempo de residência da água é maior.

Pompêo et al. (2013), em um estudo sobre biodisponibilidade do metal $\mathrm{Cu}$ nos sedimentos do reservatório Guarapiranga, encontraram valores entre 29 e $2902,4 \mathrm{mg} / \mathrm{kg}$ e concluíram que os altos valores eram provenientes da presença de $\mathrm{CuSO}_{4}$, utilizado no controle do crescimento fitoplanctônico, especialmente de cianobactérias, fato não verificado no reservatório de Foz do Rio Claro.

Mesmo sendo um elemento essencial tanto para as plantas quanto para o homem, a ingestão em excesso e/ou inalação do $\mathrm{Cu}$ podem desenvolver nos seres humanos a doença de Wilson, inflamação intestinal e hepática, hemólise e hiperglicemia (WINTER, 1998; PAVELHAO, 2015). Já a deficiência no organismo pode levar ao surgimento de doenças como osteoporose, deficiência de glóbulos brancos e à redução da defesa imunológica (CORTECCI, 2002, TRINDADE et al., 2012). 
A)

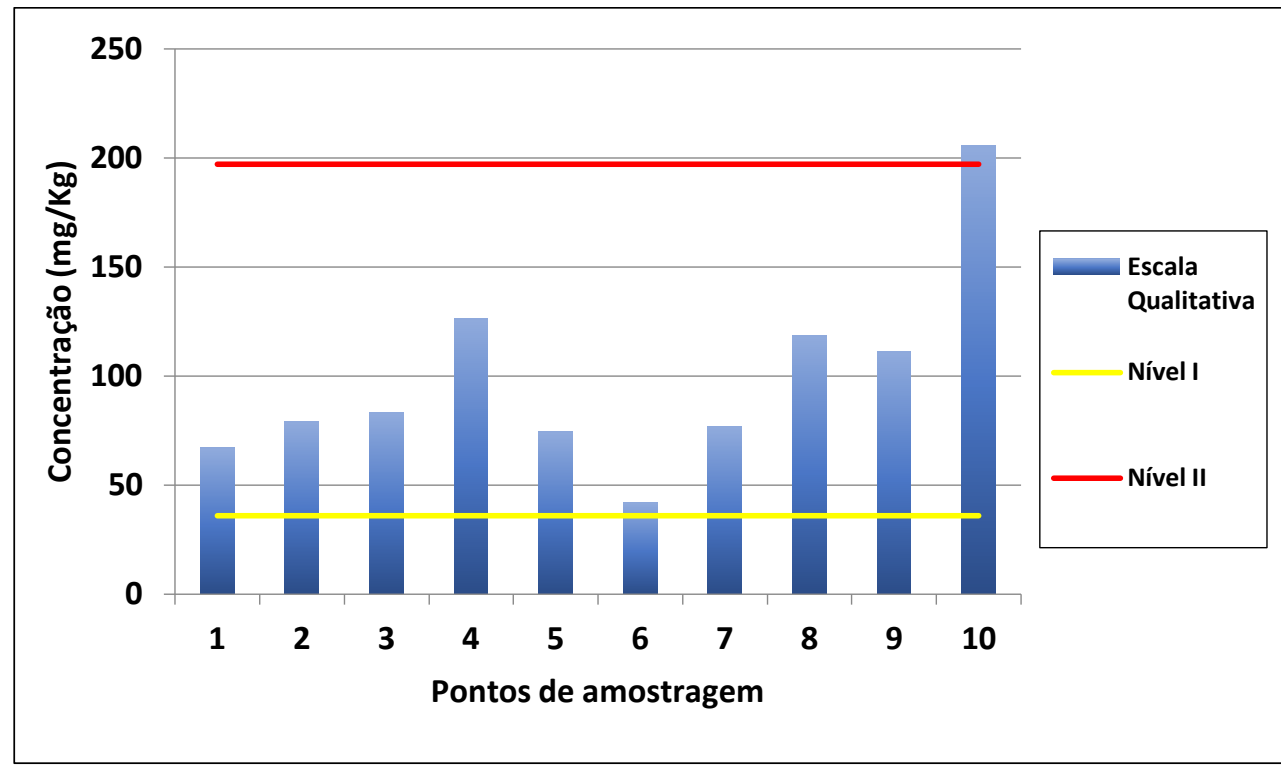

B)

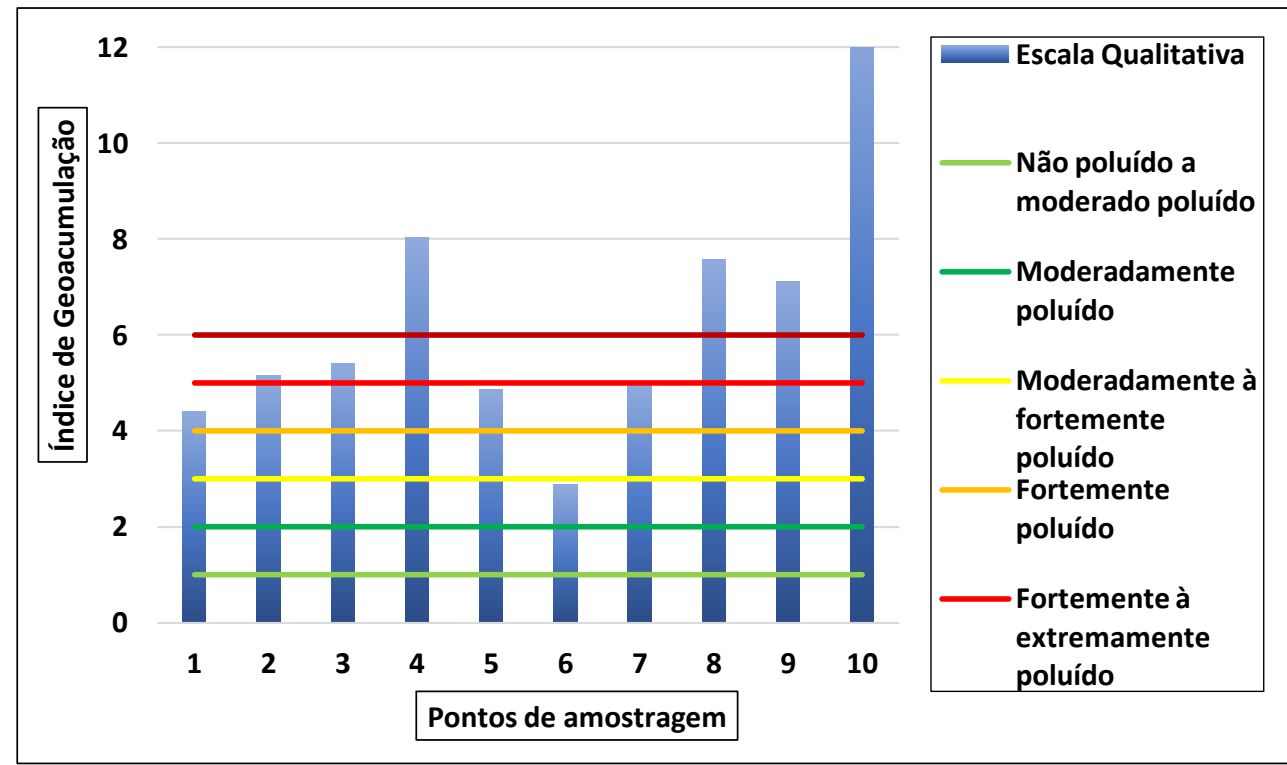

Figura 5: Concentração de $\mathrm{Cu}$ verificada nos sedimentos depositados no reservatório

Organização: Autores

Os resultados obtidos para o Cd são elevados quando comparados à Resolução CONAMA 454/2012 (Figura 6A), sendo que os valores detectados para os sedimentos são classificados acima do nível II, podendo causar efeitos adversos à biota. Em relação aos níveis de poluição propostos pelo Igeo (Figura 6B), os sedimentos do reservatório foram classificados entre Fortemente poluídos à Extremamente poluídos.

As maiores concentrações de $\mathrm{Cd}$ foram verificadas no ponto de amostragem 10 e a menor concentração no ponto de amostragem 6 , fato semelhante aos que foram detectados para os elementos $\mathrm{Zn}$ e $\mathrm{Cu}$. As altas concentrações de cádmio no ponto 10 podem ser associadas à CTC $(21,46 \mathrm{cmolc} / \mathrm{kg}), \mathrm{MO}(11,48 \%)$ e à alta concentração de material silte-argiloso $(86,54 \%)$.

Resultados semelhantes ao da presente pesquisa foram verificados por Martins et al. (2017), para o Lago Bonsucesso (GO), que se localiza na bacia do rio Claro em Goiás, distante aproximadamente $200 \mathrm{~km}$ da UHE Foz do Rio Claro, com resultados acima do nível II. Esses resultados também foram obtidos por Silva et al. (2017) na pesquisa realizada para os reservatórios Guarapiranga e Rio Grande. Em ambas as pesquisas, as prováveis fontes poluidoras para o elemento foram relacionadas com atividades antrópicas proporcionadas principalmente pelas atividades agropastoris, que fazem uso de fertilizantes e pesticidas que podem estar entrando no ambiente aquático, fato esse semelhante ao que ocorre na bacia da UHE Foz do Rio Claro. 
A)

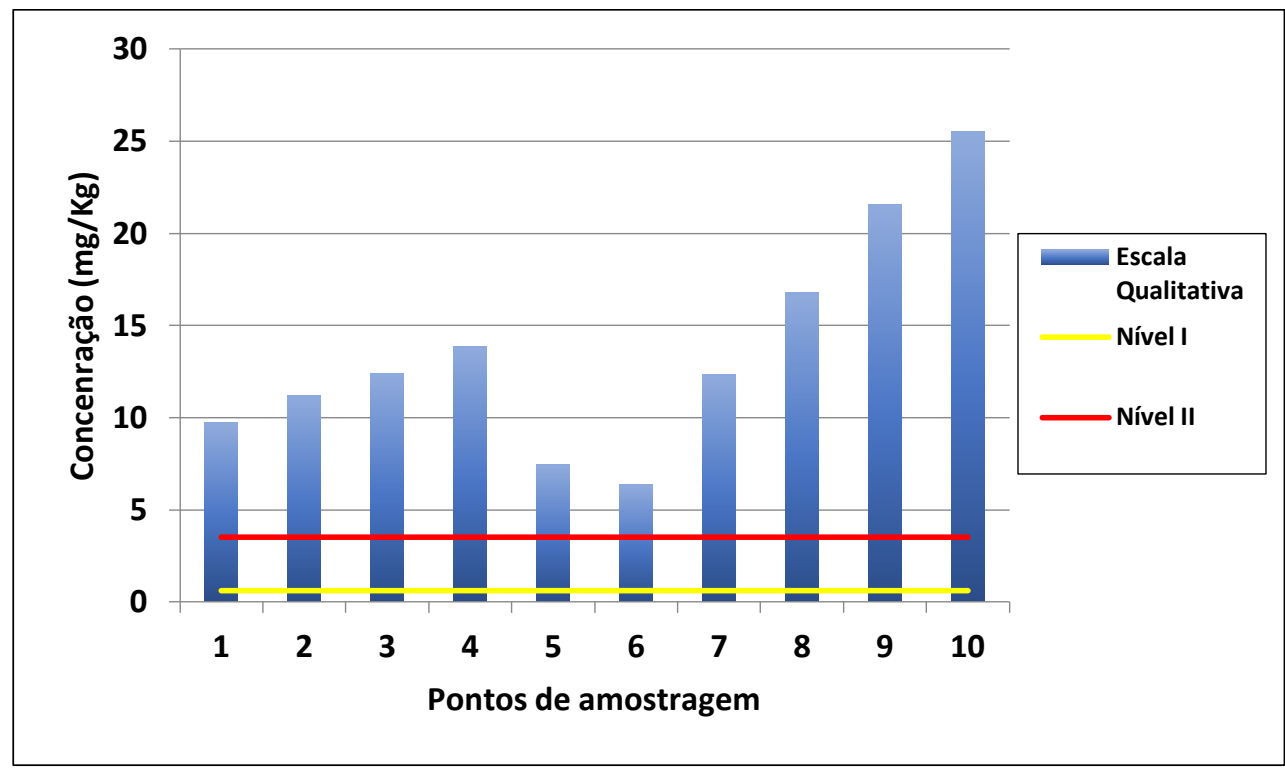

B)

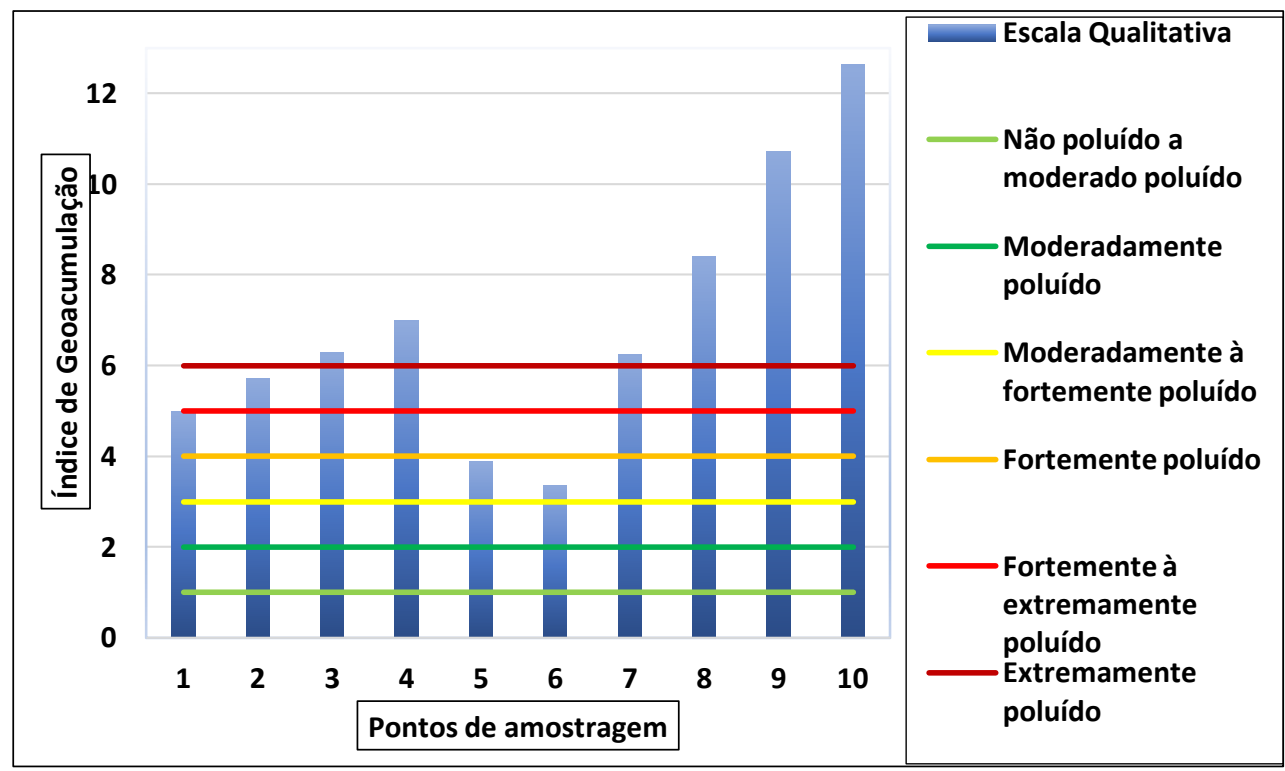

Figura 6: Concentração de Cd verificada nos sedimentos depositados no reservatório.

Organização: Autores

Zhu et al. (2017), ao aplicarem o índice de geoacumulação (Igeo) para reservatórios do nordeste da China verificaram que o $\mathrm{Cd}$ foi fortemente enriquecido por fontes antrópicas, com influência das áreas urbanas e rurais que os utilizam para abastecimento, irrigação e descarga de efluentes. Os níveis de contaminação verificados possuem potencial risco ecológico, sendo que as concentrações aumentaram em direção à barragem, característica que foi verificada no estudo da UHE Foz do Rio Claro.

O Cd apresentou concentrações que ficaram acima do permitido pela Resolução CONAMA nº 454/2012 e pelo Igeo, demostrando que existe a necessidade de investigação desse metal em relação ao modelo de uso da terra da bacia hidrográfica do empreendimento hidrelétrico, pois, o mesmo pode estar acarretando prejuízos ambientais que comprometem a qualidade da produção agropastoril e da biodiversidade existente.

\section{Conclusão}

Pode-se concluir com a presente pesquisa que, ao se modificar a paisagem natural com a construção do empreendimento de Foz do Rio Claro, alterou-se toda a dinâmica ambiental, o que gerou aumento na concentração dos metais potencialmente tóxicos. Toda essa alteração - ocasionada por atividades antrópicas têm como consequência a degradação ambiental dos sedimentos e águas, sendo os reservatórios receptores de todos os impactos ambientais. 
Com base nos resultados obtidos para os sedimentos em questão, foi possível verificar, no que concerne à Resolução CONAMA 454/2012, que os sedimentos do reservatório foram enquadrados dentro do Nível I para o metal Chumbo e do Nível II para o Cádmio.

Esses resultados demonstram que o processo de antropização pode ser um dos responsáveis para a contaminação dos sedimentos por metais potencialmente tóxicos na área da pesquisa, visto que os valores obtidos estão acima do limiar exigido pela resolução vigente.

A aplicação do Igeo para a pesquisa visou aprofundar a análise dos resultados de MPT, visto que foi registrada a falta desse tipo de estudo para a região. Os resultados, com a aplicação do Igeo, quando comparados à legislação vigente, indicam que os sedimentos são considerados de moderadamente poluídos à extremamente poluídos, o que pode indicar um comprometimento quanto à qualidade desses sedimentos para o reservatório.

Sendo assim, recomenda-se o monitoramento contínuo dos metais pesados na bacia do rio Claro, a fim de investigar suas origens, e a recomposição da cobertura vegetal, que atuam como filtro na entrada de materiais no curso d'água. A proposta visa que seja aplicada a legislação vigente para o desenvolvimento e utilização de técnicas e medidas mitigadoras voltadas à redução dos impactos ocasionados pelas atividades antrópicas.

\section{Referências}

ABRID, D.; EL HMAIDI, A.; ABDALLAQUI, A.; ESSAHLAQUI, A. Study of Trace Metals in Surface Sediments of the Dam Reservoir Sidi Chahed (Meknes, Morocco). The International Journal of Engineering And Science, 2014. Pp23-32.

ALI, H.; KHAN, E.; ILAHI.I Environmental chemistry and ecotoxicology of hazardous heavy metals: environmental persistence, toxicity, and bioaccumulation. J. Chem. 2019, pp.1-14. https://doi.org/10.1155/2019/6730305

AN YJ, KAMPBELL D.H. Total, dissolved, and bioavailable metals at Lake Texoma marinas. Environ Pollut. 2003;122(2):253-259. https://doi:10.1016/s0269-7491(02)00291-9

BELO, A.; QUINÁIA, S. P.; PLETSCH, A. L. Avaliação da contaminação de metais em sedimentos superficiais das praias do lago de Itaipu. Química Nova, 2010. 33(3), 613617. https://doi.org/10.1590/S0100-40422010000300024

BERGMANN, M.; SILVEIRA, C. A. P.; BAMBERG, A. L.; MARTINAZZO, R.; GRECCO, M. F. Considerações sobre o potencial de uso agronômico das rochas vulcânicas da Formação Serra Geral da Bacia do Paraná. In: HARTMANN, L.A.; SILVA, J. T. DA; DONATO, M. (Org.). Tecnologia e Inovação em Gemas, Jóias e Mineração. Porto Alegre: UFRGS, 2014, p. 119-126.

BERTRAND, G. Paysage et géographie physique globale, esquisse méthodologique. Revue Géographique des Pyrénées et du Sud-Ouest. Toulouse, 39, 3, p. 249-272, 1968.

BOULET, R; LUCAS, Y; FRITSCH, E; PAQUET.H. Geoquímica das paisagens tropicais: o papel das coberturas pedológicas. Revista do Instituto Geológico, 2016, 37 (2), 1-23.

BRAGA, C. C.; CABRAL, J.B.P.; LOPES, S.M.F.; OLIVEIRA, S. F.; ROCHA, I. R. Qualidade dos sedimentos em relação à presença de metais pesados no reservatório da usina hidrelétrica de Caçu - GO. Revista Brasileira de Geografia Física. 2018. v.11, n.03. https://doi.org/10.26848/rbgf.v11.3.p959-972

CARDOSO-SILVA, S., MEIRELLES, S.T., FRASCARELI, D. Metals in superficial sediments of a cascade multisystem reservoir: contamination and potential ecological risk. Environ Earth Sci 2017, 76, 756. https://doi.org/10.1007/s12665-017-7104-9 
CAMPBEll, P., G.; C.; LEWIS, A., G.; CHAPMAN, P., M.; CROWDER, A., A.; FLETCHER, W. K.; IMBER, B.; LUOMA, S., N.; STOKES, P., M.; WINFREY, M. Biologically available metals in sediments. 1988. Publications NRCC/CNRC, Ottawa, Canadá, 298p.

CAVALCANTI, L. C. S.; CORREA, A. C B. ARAÚJO FILHO, J.C. Fundamentos para o mapeamento de geossistemas: uma atualização conceitual. Geografia. 2010, 35(3). 539-551.

CAVALCANTI, L. C. S.; CORREA, A. C B. Geossistemas e Geografia no Brasil. Revista Brasileira de Geografia. 2016, 61(02), p. 3-33.

CESAR, R.; COLONESE, J.; SILVA, M.; EGLER, S.; BIDONE, E.; CASTILHOS, Z.; POLIVANOV, H. Distribuição de mercúrio, cobre, chumbo, zinco e níquel em sedimentos de corrente da bacia do Rio Piabanha, Estado do Rio de janeiro. Geochimica Brasiliensis, v. 25, n. 1, p. 35-45, 2011. https://doi.org/10.21715/gb.v25i1.330

CETESB. Relatório de qualidade de águas interiores no Estado de São Paulo. 2005. Disponível em: https://cetesb.sp.gov.br/aguas-interiores/publicacoes-e-relatorios/.

CETESB. Relatório de qualidade de águas interiores no Estado de São Paulo. 2016. Disponível em: https://cetesb.sp.gov.br/aguas-interiores/publicacoes-e-relatorios/.

COMPANHIA DE PESQUISA DE RECURSOS MINERAIS, CPRM/ Geologia médica no Brasil: efeitos dos materiais e fatores geológicos na saúde humana, animal e meio, 2006.

CONSELHO NACIONAL DO MEIO AMBIENTE. MINISTÉRIO DO MEIO AMBIENTE [CONAMA]. Resolução $\mathrm{n}^{\circ} \quad 454 \quad 01$ de novembro de 2012. Disponível em: http://www2.mma.gov.br/port/conama/legiabre.cfm?codlegi=693.

CONSILIU MEIO AMBIENTE \& PROJETO. Relatório Semestral Do Pacuera da Usina Hidrelétrica Foz do Rio Claro. Plano Ambiental De Controle e Uso do Entorno de Reservatórios Artificiais UHE Foz do Rio Claro. 2007

COPAJA, S. V.; NUÑEZ, V. R.; MUÑOZ, G.; GONZÁLEZ, G. L.; VILA, I; VÉLIZ, D. Heavy Metal Concentrations in Water and Sediments from Affluents and Effluents of Mediterranean Chilean Reservoirs. Journal of the Chilean Chemical Society, 2016. 61(1), 2797-2804. https://dx.doi.org/10.4067/S0717$\underline{97072016000100011}$

CORTECCI G. Geologia e saúde. Trad. Wilson Scarpelli. 2002. Disponível em: http://www.cprm.gov.br/pgagem/artigoind.htm.

COSTA, J. M. B. S.; SILVA, V.L; SAMICO, I.C.; CESSE, E.A.P. Desempenho de intervenções de saúde em países da América Latina: uma revisão sistemática. Saúde debate [online]. 2015, vol.39, pp.307-319. ISSN 2358-2898.https://doi.org/10.5935/0103-1104.2015S005307.

DABROWSKA, L. Chemical Forms of Heavy Metals In Bottom Sediments Of The Mitręga Reservoir. Civil and Environmental Engineering Reports, CEER 2016; 21 (2): 015-026 DOI: 10.1515/ceer-2016-0017

DANTAS, M. E., ARMESTO, R. C. G., SILVA, C. R. DA, \& SHINZATO, E. Geodiversidade e análise da paisagem: uma abordagem teórico-metodológica. Terra e Didática, $2015.411(1), \quad 4-13$. https://doi.org/10.20396/td.v11i1.8637304 
DORIA, H. B.; VOIGT, C. L.; CAMPOS, S. X.; RANDI, M. A. F. Metal pollution assessment in a Brazilian hydroelectric reservoir: Geophagus brasiliensis as a suitable bioindicator organismo. Rev. Ambient. Água. 2017, vol.12, n.4, pp.575-590. http://dx.doi.org/10.4136/ambi-agua.2061.

ESTEVES, F.A. Fundamentos de Limnologia. INTERCIÊNCIA (Ed.), 1998. Rio de Janeiro, 226p.

EMBRAPA - Empresa Brasileira de Pesquisa Agropecuária. Manual de métodos de análises de solos. Centro Nacional de Pesquisa de Solos. - 2. ed. rev. atual. 1997 - Rio de Janeiro.

EMBRAPA - Empresa Brasileira de Pesquisa Agropecuária. Sistema Brasileiro de Classificação de Solos / Humberto Gonçalves dos Santos ... [et al.]. - 5. ed., rev. e ampl. 2018 - Brasília, DF: Embrapa.

FILIZOLA, H. F. Manual de procedimentos de coleta de amostras em áreas agrícolas para análise da qualidade ambiental: solo, água e sedimentos. Embrapa Meio Ambiente, 2006.

FORTESCUE, J. A. C. Landscape geochemistry: retrospect and prospect-1990. Applied Geochemistry.1992, https://doi.org/10.1016/0883-2927(92)90012-R

FRANÇOZO, M. O.; OLIVEIRA, T. M. N.; RESSEL, K. Análise da Presença de Metais Pesados e sua Toxicidade nos Sedimentos do Rio Cachoeira - Joinville/SC. IX Simpósio Internacional de Qualidade Ambiental, Energia e Ambiente. Pp. 1-15. 2014.

FRANKLIN, R.L.; FÁVARO, D.I.T.; DAMATTO, S.R. Trace metal and rare earth elements in a sediment profile from the Rio Grande Reservoir, São Paulo, Brazil: determination of anthropogenic contamination, dating, and sedimentation rates. J Radioanal Nucl Chem. 2016. 307, 99-110. https://doi.org/10.1007/s10967-015-4107-4

FRANZ, C.; MAKESCHIN, F.; WEIB, H.; LORZ, C. Geochemical signature and properties of sediment sources and aluvial sediments within the Lago Paranoá catchment, Brasilia DF: A study on anthropogenic introduced chemical elements in an urban river basin. Sci Total Environ. 2013; 452-453:411-420. http://doi:10.1016/j.scitotenv.2013.02.077

FROHLICH, M. F.; NASPOLINI, B. F.; VOLSCHAN JUNIOR.I. A evolução do processo de avaliação e gerenciamento de material relacionado às atividades de dragagem no Brasil: Uma análise comparativa entre as Resoluções CONAMA n 344/04 e n 454/12. Engenharia Sanitaria e Ambiental, 2015. 20(1), 131140. https://dx.doi.org/10.1590/S1413-41522015020000123410

FU F, WANG Q. Removal of heavy metal ions from wastewaters: a review. J Environ Manage. 2011;92(3):407-418. https://doi:10.1016/j.jenvman.2010.11.011. 2011.

GAIDOUMI, A. E. L.; TANJI, K.; BenABDAllaH, A. C.; TAlEB, A.; KHERBECHE, A. Characterization and Quantification of Heavy Metals in Oued Sebou Sediments. Hindawi The Scientifc World Journal, 2019. pp 1-9. https://doi.org/10.1155/2019/7496576

GOMES, M. V.; T; COSTA, A. S.; GARCIA, C. A. B.; PASSOS, E. A.; ALVES, J. P. H. X Concentrações e associações geoquímicas de $\mathrm{Pb}$ e $\mathrm{Zn}$ em sedimentos do rio São Francisco impactados por rejeitos da produção industrial de zinco. Química Nova, 2010. 33(10), 2088-2092.https://doi.org/10.1590/S0100$\underline{40422010001000016}$

HORTELLANI, M. A.; SARKIS, J.E.S.; MENEZES, L. C. B.; BAZANTE-YAMAGUISHI, R.; PEREIRA, A. S. A.; GARCIA, P. F. G.; MARUYAMA, L. S.; CASTRO, P. M. G. Assessment of metal concentration 
in the Billings Reservoir sediments, São Paulo State, Southeastern Brazil. Journal of the Brazilian Chemical Society, 2013. 24(1), 58-67. https://doi.org/10.1590/S0103-50532013000100009

JACKSON, M. L. Soil Chemical Analysis Prentice Hall of Englewood cliffs, New Jersey, USA, 1967.

KIM, S.; YANG, D.S.; KIM, Y.S. Distribution of metal contamination and grain size in the sediments of Nakdong River, Korea. Environ Monit Assess 192, 502. 2020. https://doi.org/10.1007/s10661-020-08475-Z

KOROBOVA, E. M., VELDKAMP, A., KETNER, P., KROONENBERG, S. B. Element partitioning in sediment, soil and vegetation in an alluvial terrace chronosequence, Limagne rift valley, France: A landscape geochemical study. Catena. 1997, 31(1-2), 91-117. https://doi.org/10.1016/S0341-8162(97)00029-5

LICHT, O.A.B; XUEJING. X; QIN, Z; MIYAZAWA, M; FERREIRA, F.J.F; PLAWIAK, R.A.B (2006). Average references values of geochemical and geophysical variables in stream sediments and soils, State of Paraná, Brazil. Boletim Paranaense de Geociências. 2006, n. 58, 59-87.

LICHT, O.A.B; BITTENCOURT, A.V. L (2013) Paisagens geoquímicas naturais e antrópicas no estado do Paraná. Revista Técnico Cientifica do Crea - PR. 2013, N1. 1-27.

LOPES, R. M.; MARIANO, Z. F. ANÁLISE DOS EPSÓDIOS DE VERÃO E INVERNO NA ÁREA DE INFLUÊNCIA DOS RESERVATÓRIOS CAÇU E BARRA DOS COQUEIROS-GO. Geoambiente OnLine, 2018. (30). https://doi.org/10.5216/revgeoamb.v0i30.52925

MARQUES, J. J., SCHULZE, D. G., CURI, N., \& MERTZMAN, S. A. (2004). Major element geochemistry and geomorphic relationships in Brazilian Cerrado soils. Geoderma. 2004, 119(3-4), 179-195. https://doi.org/10.1016/S0016-7061(03)00260-X

MARTINAZZO, R; SILVEIRA, C.A.P; BAMBERG, A.L; STUMPF, L; STOCKER, C, M; MONTEIRO, A.B; PEREIRA, I.S; RIBEIRO, P.L; GIACOMINI, S.J. Incorporation of retorted oil shale in Brazilian agricultural soil: An assessment of impacts after successive applications. Journal of Cleaner Production. 2020, 118652.

MARTINS, R. O.; BRAIT, C. H.; SANTOS, F. F. dos. AVALIAÇÃO DO TEOR DE METAIS PESADOS E DE PARÂMETROS FÍSICO-QUÍMICOS DA ÁGUA E SEDIMENTO DO LAGO BONSUCESSO, JATAÍ - GO. Geoambiente On-Line, 2018. (29). https://doi.org/10.5216/revgeoamb.v0i29.51072

MATTOS, A.G.; AMARAL SOBRINHO, N.M.B.; LIMA, E.S.A.; GUEDES, J.N.; SOUSA, F.F. Sorção de $\mathrm{Cd}$ e $\mathrm{Pb}$ nos solos da região do Médio Rio Paraíba - RJ, Brasil. Revista Ciência Agronômica. 2016, v. 47, n. 1, p. 1-12, DOI: 10.5935/1806-6690.20160001.

MAZZILLI, B.P., A, SAUEIA, C. H. R. A.; JACOMINO, V. M. F. B.; MELLO, J. W.V. Natural radionuclides and metals intake into soya, corn and lettuce grown on soil amended with phosphogypsum. International Journal of Environmental Analytical Chemistry. 2011, 92,1574 -1586. https://doi.org/10.1080/03067319.2010.549339

MOORE, J.W., SUTHERLAND, D.J. Distribution of heavy metals and radionuclides in sediments, water, and fish in an area of Great Bear Lake contaminated with mine wastes. Arch. Environ. Contam. Toxicol. 1981, 329-338. https://doi.org/10.1007/BF01055634

MULLER, G. Index of geoaccumulation in sediments of the Rhine River. Geological Journal, 1969. 2, 109118. 
NAKASHIMA, M. R. ALVES, G. B.; BARREIROS, A. M.; QUEIROZ NETO, J. P. Dos solos à paisagem: uma discussão teórico-metodológica. Revista da ANPEGE. 2017, 30-52. https://doi.org/10.5418/RA2017.1320.0003.

NASCIMENTO, L. P.; REIS, D. A.; ROESER, H. M. P.; SANTIAGO, A.F. Avaliação Geoquímica de Metais em Sistemas Fluviais Afetados por Atividades Antrópicas no Quadrilátero Ferrífero. Engenharia Sanitária e Ambiental, 2018. 23(4), 767-778. https://dx.doi.org/10.1590/s1413-41522018165852

NOGUEIRA, P. F.; CABRAL, J.B.P.; OLIVEIRA, S.F.; ROCHA, I.R. (2015). Eutrofização no reservatório da UHE Foz do Rio Claro (GO). Revista Do Departamento De Geografia, 30, p. 19-33. 2015. https://doi.org/10.11606/rdg.v30i0.90090

OLIVEIRA, G. M. T. S.; OliVEIRA, E. S. SANTOS, M. DE L. S.; MELO, N. F. A. C.; KRAG, M. N. Concentrações de metais pesados nos sedimentos do lago Água Preta (Pará, Brasil). Engenharia Sanitária e Ambiental, 23(3), 599-605. https://doi.org/10.1590/s1413-41522018152875

PAVELHAO, T. R. Valores Orientadores De Qualidade Para Metais Pesados Em Solos Cultivados No Município De Bandeirantes - PR Tese (Doutorado) ao Programa de Pós-Graduação em Geografia da Universidade Estadual de Maringá. 2015.

POLETO, C.; MERTEN, G.H. Elementos traço em sedimentos urbanos e sua avaliação por guidelines. Holos Environment, v. 8, n. 2, pp. 100-118, 2008. https://doi.org/10.14295/holos.v8i2.3047

POMPÊO, M.; PADIAL, P. R.; MARIANI, C. F.; SILVA, S. C.; CARLOS, V. M.; SILVA, D. C. V. R da.; PAIVA, T. C. B. de.; BRANDIAMARTE, A. L. Biodisponibilidade de Metais no Sedimento de um Reservatório Tropical Urbano (reservatório Guarapiranga - São Paulo (SP), Brasil): há Toxicidade Potencial e Heterogeneidade Espacial. Geochimica Brasiliensis 27(2): 104-119, 2013. https://doi.org/10.21715/gb.v27i2.364

QUEIROZ JUNIOR, V.S.; CABRAL, J.B.P.; ROCHA, I.R.; BARCELOS, A.A. Uso de geotecnologias na caracterização da fragilidade ambiental da Bacia da UHE Foz do Rio Claro (GO). GeoFocus, 2014. n 15, p. 193-212.

RAMALHO, J.F.G.P; AMARAL SOBRINHO, N. M, B; VELLOSO, A, C, X. Contaminação da microbacia de Caétes com metais pesados pelo uso de agroquímicos. Pesquisa Agropecuária Brasileira, Brasília. 2000, V35. N7. P.1289-1303.

RAMOS, M., DE ABREU, M., GUIZZO, J., CORDEIRO, D., \& FERREIRA, P. Contaminação por metais pesados em áreas agrícolas no estado do Tocantins. Tecno-Lógica. 2020, 24(2), 166-178.

doi:https://doi.org/10.17058/tecnolog.v24i2.14845

RODRIGUEZ, J. M. M.; SILVA, E. V. Planejamento e gestão ambiental: subsídios da geoecologia das paisagens e da teoria geossistêmica. Fortaleza: Edições UFC, 2013.

SANTOS, R. I. DOS.; BRAGA, N. A.; RECKTENVALD, M C. N. N.; CARVALHO, D.P.; MIRANDA.M. R.; MANZATTO, A. G.; BASTOS, W. R. Metais em sedimentos de fundo na bacia do alto Rio Madeira, Bacia Amazônica. Scientia Amazonia, v.4, 2015. http://dx.doi.org/10.19178/Sci.Amazon.v4i1.91-100

SANTOS, F.C; CONFESSOR, J.G. Geoquímica e geocronologia em campos de murunduns no Chapadão do Diamante -Serra da Canastra-MG. Caderno de Geografia, 2020. v.30, Número Especial 1, 99-111. 
SIEG. Sistema Estadual de Estatísticas Informações Geografias de Goiás. Disponível em: <http://www.sieg.go.gov.br>. 2011.

SILVA, L. S; FERREIRA, F. J; FÁVARO, D. I. T. Avaliação da Concentração de Metais Tóxicos em Amostras de Sedimentos dos Reservatórios do Complexo Billings (Guarapiranga e Rio Grande). Geochimica Brasiliensis 2017. 31(1): 37 - 56.

SILVA, F. L.; MOITAS, M. L.; BIANCHINI JR, I.; CUNHA-SANTINO, M. B. Qualidade dos sedimentos do rio Monjolinho: índice de geoacumulação. Revista Ciência Tecnologia \& Ambiente, 2016. v. 4, n 1, p. 79-87.

SOJKA, M.; JASKUŁA, J.; SIEPAK, M. Heavy Metals in Bottom Sediments of Reservoirs in the Lowland Area of Western Poland: Concentrations, Distribution, Sources and Ecological Risk. Water. 2019, 11, 56.

SOUZA, M. J. B. de. Avaliação de Metais-Traço no Sedimento do Sistema Estuarino dos Rios Piraquê-Açu e Piraquê-Mirim (Aracruz - es). Dissertação apresentada ao Programa de Pós-Graduação em Química do Centro de Ciências Exatas da Universidade Federal do Espírito Santo, 2009.

STEVANOVIĆ V, GULAN L, MILENKOVIĆ B, VALJAREVIĆ A, ZEREMSKI T, PENJIŠEVIĆ I. Environmental risk assessment of radioactivity and heavy metals in soil of Toplica region, South Serbia. Environ Geochem Health. 2018;40(5):2101-2118. doi:10.1007/s10653-018-0085-0

TRINDADE, W. M.; HORN, A. H.; RIBEIRO, E. V. Concentrações de Metais Pesados em Sedimentos do Rio São Francisco Entre Três Marias e Pirapora-MG: Geoquímica e Classificação de Risco Ambiental. Geonomos, 20(1), 64-75, 2012. https://doi.org/10.18285/geonomos.v20i1.28

USEPA - U.S. Environmental Protection Agency, 2007. SW-846 3051a: Microwave assisted acid digestion of sediments, sludges, soils and oils, Revision 1. U.S.: U.S. EPA

ZHU, L.; LIU, J.; XU, S.; \& XIE, Z. Deposition behavior, risk assessment and source identification of heavy metals in reservoir sediments of Northeast China. Ecotoxicology and Environmental Safety, 2017. 142, 454-463. https://doi.org/10.1016/j.ecoenv.2017.04.039

WINTER M. 1998. Web-Elements. Disponível em: http://www.shef.ac.uk/ chem/web-elements.

YAKOVLEV, E.Y., ZYKOVA, E.N., ZYKOV, S.B.; MALKOV, A. V.; BAZHENOV, A. V. Heavy metals and radionuclides distribution and environmental risk assessment in soils of the Severodvinsk industrial district, NW Russia. Environ Earth Sci 79, 218 (2020). https://doi.org/10.1007/s12665-020-08967-8

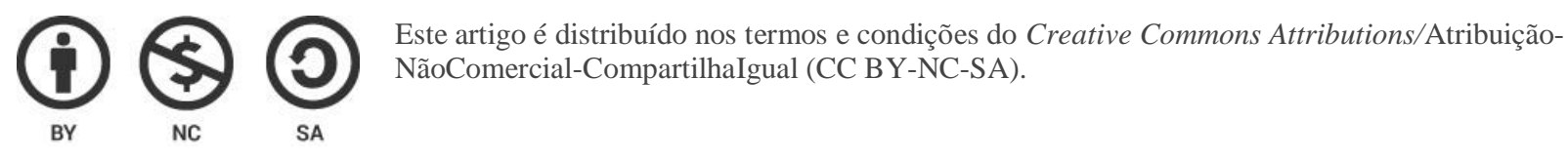

